\title{
Rhetorical and Linguistic Analysis of Bush's Second Inaugural Speech
}

\author{
Imad Hayif Sameer \\ Department of English, University of Anbar, Iraq \\ E-mail: emadhaif@yahoo.com
}

Doi:10.7575/aiac.alls.v.8n.1p.44

Received: 02/09/2016

URL: http://dx.doi.org/10.7575/aiac.alls.v.8n.1p.44

Accepted: 28/12/2016

\begin{abstract}
This study attempts to analyze Bush's second inaugural speech. It aims at investigating the use of linguistic strategies in it. It resorts to two models which are Aristotle's model while the second is that of Atkinson's (1984) to draw the attention towards linguistic strategies. The analysis shows that Bush's second inaugural speech is successful because it manifests and achieves these strategies.
\end{abstract}

Keywords: Discourse, Critical Discourse Analysis, Rhetoric, Politics and Language, Inaugural Speech

\section{Introduction}

The speaker's knowledge and experience determine delivering well- understood and accurate speeches. Politicians should be experts to win and gain the support they want when they speak in public. If anyone of them feels unconfident of what he is saying, he may lose the confidence expected from the audience. This study will focus on analyzing Aristotle's elements and identifying the linguistic strategies as proposed by Atkinson. It will include definition of critical discourse analysis, rhetoric and clarifying the relationship between language and politics. It also sheds light on hidden features found in this genre of speech that are used to generate certain impacts inside the hearers. The form of Bush's speech traces most of the preceded ones because it consists of four parts which are respectively the prologue, the narrative, the proof and the epilogue. The results also show that the use of the artistic proofs as a whole is identical to what presented by Aristotle. Most of linguistic strategies are manifested in the speech under the study.

\section{Literature Review}

\subsection{Critical Discourse Analysis (CDA)}

According to Wodak (1997:173), the central focus of CDA is on power, and especially reproduced power. Its main objective is to analyze and understand the aspects of discrimination, control, power and dominance as appeared and manifested in language. She (ibid) argues that the most important goal of CDA is to understand and study the relationship between language and society and clarify that between analysis and the topics analyzed.

Chouliaraki and Fairclough (1999:4) claim that discourse is socially constitutive and its meaning is only determined by society. Discourse is an instrument of power and the work of this instrument is hard to understand but it can be clarified by CDA.

They (ibid: 33) argue that critical discourse analysis focuses on studying the intersection of language /discourse/speech and social structure. Discourse patterns (in the form of ideological effects and power relations) which are related by social structures are treated as problematic by the researchers who imply critical dimension of their work.

They likewise assert that it is hard to rely on upon social measurements to understand language since they are the question of political and moral evaluation. The investigation of them have impacts in society: enabling the weak, offering voice to the voiceless, activating individuals to remedy social wrongs and exposing the aspects of power abuse.

\subsection{Rhetoric}

Burke (1969:72) states that," Wherever there is persuasion, there is rhetoric .And wherever there is meaning, there is persuasion". Cyphert (2010:346-364) mentions that sometimes, Rhetoric may be seen as a synonym of discourse, and often it can be used interchangeably with ideology. Its main focus is on persuasion. Its definition implies the notion of power. Rhetorical studies seek to explain the way by which language and other symbols influence or affect the audience's thinking, feelings, and actions. Rhetorical works harmonically with discourse but it does not really frame a subset of discourse analysis. Its analysis seeks to understand the reasons which create specific social effects in discourse.

Holt, R.,\& MacPherson, A (2010: 20-42), state that the classical rhetoric is distinguished by three distinct elements which are not separable. These are Aristotle's elements of ethos (credibility), logos (reason), and pathos (emotions). These elements help revealing the factors of a good argument, and identifying and presenting the dimensions of good persuasion. 
Sillince \& Suddaby (2008:6) argue that the most important element of everyday interaction and communication is rhetoric which represents the core form of any communication making its actions more coordinated.

According to (Plett, 2001:27-32) Political rhetoric can be defined as the practical art of speaking and writing well in public sphere through the use of various communicative genres. It is the theory of eloquence. It is not only connected with the use of flowery figurative speech but the qualification of good is conceived in much wider sense that goes far beyond the question of poetic aestheticism or ornamental language. It is related to principles such as clarity and understandability, grammatical correctness, evidence or vividness, and adequacy with respect to the speaker or writer, hearer or reader, the situation and the topic.

It can be said that the most central to this term is that it is the art of effective or efficient speaking and writing in public. In short, it is the science or art of persuasive language use. The three crucial objectives of such persuasion are logos, ethos and pathos (ibid 1-4)

\subsection{Politics and Language}

Meyer (2000:52-99) differentiates among three dimensions: polity, policy and politics. The first dimension implies the formal and structural framework as being the basis of political action. It can be manifested in basic political norms, principles, rules and values of a political culture, legal procedures and political institutions of a political system designated to found political order. Its objectives are logos and ethos, particularly political legitimization, control and education. Political identity can be added to these objectives.

He (ibid) states that policy implies the content-related dimension of political action that seeks to achieve shaping the various political institutions (ministries) perform it. Domestic affairs, foreign policy, economic policy, social policy manifest policy. Planning and articulation of governmental tasks and programmes reflect it or related to it. It is bureaucratic (administrative decisions and programmatic).Its main goals such as political justification, political instruction and winning political allies.

He (ibid) also mentions that politics can be reflected by the articulation of political interest and positions of dissent or consent. Conflicts among single or collective political actors are one of its characteristics. In this dimension, political actors try to assert themselves against opponents, to gain followers, and to persuade addressee to adopt a promoted political opinion. There are two strands to define Politics. The first strand views politics as a struggle of power, between those who seek to assert and maintain their power and those who seek to resist it. In the second strand, politics may be viewed as cooperation, as the practices and the institutions that of interests over money, influence, liberty and the like.

Jones et al (1994: 5) state that in addition to these two orientations, the distinction between micro and macro levels can be manifested. At the first level, the conflicts of interests are appeared, struggle for dominance are manifested and the variation of efforts of co-operation and coordination between individuals between genders and between social groups are identified.

At the macro level, institutions of the state which aim at asserting the power of a dominant individual (a tyrant) or a group. Associated with these state institutions, are parties and talent politicians, with more or less stable practice, social movements and other social formations.

The micro-level manifests the linguistic action (discourse) while the macro- level institutions are types of discourse that carry or have specific characteristics.

Hague et al (1998: 3-4) state that the political process typically implies or involves persuasion and bargaining, therefore, the use of language to create the effects of authority, consensus, legitimacy are recognized as being intrinsic to politics. Politics implies a linguistic, discursive and communicative dimension.

Wodak (2000: 4) states that language and politics are linked at a fundamental level. This relation is manifested by Aristotle's celebrated definitions of humans describing them as creatures whose nature is to live in a polis. Nature has endowed or distinguished man alone among the animals with the power of speech. He distinguishes 'speech' from ' voice'. The voice is the characteristic of all animals which serves or helps to communicate or convey feelings of pleasure and pain while the uniquely human speech helps indicating what is useful and what is harmful, and also what is just and what is unjust. This means that human alone has an unique perception of good and evil, just and unjust. These matters which indicate or appoint what is useful and harmful, just and unjust make or form a household and a state.

She(ibid:6)mentions that even though Aristotle does not pursue or notice the connection between the linguistic and political make- up of humans, but his implications or definition have an important role. According to linguists, the human capacity for speech is genetically based and human social relations activate it and give it meaning. The question is how the genetic base itself evolved. Did the social intelligence evolve it? Aristotle advocates this view. Or did the random mutation evolve it and, provide neural structures that guided to the duality and generative characteristics of human language. What is clear is that political activity cannot exist without the use of language. Political activity involves other behaviors but the doing of politic is predominantly constituted in language.

\subsection{Previous Studies}

The first study is that presented by Horvath with the title" Critical Discourse Analysis of Obama's Political Discourse". In this study, the researcher grounds his analysis in Norman Fairclough's assumptions when he states that ideologies reside $\mathrm{n}$ texts and it is impossible to read off them from texts. For this reason, texts can be interpreted differently. The 
researcher tackles the first sentence uttered by Obama as a sample of ideological analysis. Obama says," My fellow citizens: I stand here today humbled by the task before us, grateful for the trust you have bestowed, mindful of the sacrifices borne by our ancestors". This sample shows that Obama's speech is more inclusive because it includes all nationalities and ethnicities. It applies a more citizen - entered attitude. This study concludes that the key ideological components of Obama's speech are acceptance of religions and ethnic diversity and unity, pragmatism, liberalism and inclusiveness. Biblical references are used by the president to strengthen the notion of unity and brotherly love among the various members of the American diverse society.

Wang, J. (2010) presents his work which is entitled with," A Critical Discourse Analysis of Barack Obama's Speeches". Critical discourse analysis theory and systematic functional linguistics form the base of this study. Barack Obama's presidential speeches are mainly analyzed from the point of transitivity and modality to investigate how language serves the ideology and power. The study concludes that Barack Obama uses more simple vocabularies and short sentences instead of difficult words and sentences. This feature makes the distance between the speaker and the audience too short. From another point of view, we can note material process, a process of doing, is highly used in his speech. This characteristic shows the achievements of the government and what it will do in the future. It arouses the American people's confidence towards the president and his government. He shortens the distance between him and the audience by resorting to model verbs, tense and first person pronouns. The domestic and worldwide situations ranging from political, economic and cultural fields at present are presented by using present simple tense. He moves to deal with future tense to lay out his following steps and reforms in his term. Overusing first person pronouns and religious beliefs help persuade the audience to accept and support the speaker's policies.

Peter Adamec presents his study with the title "Persuasion in Political Discourse" as a Diploma thesis in 2011. In his introduction, the researcher states that people use various methods to win their fight. Human speech forms an instrument which can serve for various purposes. This study aims at exploring how political speeches can persuade different audiences that what has been said is true. This study tries to trace the words that motivate the people to do what the politician wishes them to do in specific situation. The conclusion of this study shows that persuasive strategies are not different in the speeches. It indicates that entailment is the main device of persuasion used by Obama to make the audience accept his ideas and opinions.

The last study is that of Sahar Altikriti with the title," Persuasive Speech Acts in Barack Obama's Inaugural Speeches (2009 ,2013) and the last state of the Union Address ( 2016 ). The work is published in 2016. In this study, the researcher argues that language forms or constitutes an essential factor for politicians since politics deal with the power of setting decisions and they influence people's attitudes and control their values. The politicians want to convince their audience to change their beliefs regarding a political issue via message but this must be done by resorting to a sense of free choice. This means that persuasion forms a speech act that is realized or manifested by speaking. This study sheds light to the role of this speech act in political speeches. The study is based on Bach and Harnish Taxonomy (1979). A link between communication and persuasion mentioned by Aristotle is presented by the researcher to analyze the data. This link is motivated in terms of three main ways of persuasion:

A- Appeal by reason.

B- Appeal by ethics.

C- Emotional (aesthetical) appeal.

We can distinguish among these three modes by threefold division of styles:

1- Ethos: personality and stance are the elements of persuasion.

2- Pathos: the arousal of emotion is used to achieve the persuasion.

3- Logos: reasoning achieves persuasion.

The researcher also relies on Fotheringham's definition of persuasion when he (1966:7) states that persuasion is the creation of effects in receivers, being relevant and instrumental to source, achieving desired goals, brought about by a process in which messages have been a major determinant of those effects. Fotheringham focuses on receivers rather than on producers.

This study studies three strategies. The first one is presented by Perelman and Olbrechts-Tyleca (1969:194). It is called Quasilogical. They used it for wondering of argumentation in formal logic and mathematics. In fact, these arguments are not logical in the strict sense. The second one is called Presentational persuasion which is clearly explained by Jonestone (1989:148) as follows: It is based on the assumption that being moved, being swept along by a rhythmic flow of words or sounds as in the way people are swept along by poetry means being persuaded. Its goal is to make one's claim maximally present in the audience's consciousness by repeating it, paraphrasing it and calling aesthetic attention to it. The last strategy is that of analogy whose language is used to persuade via creating analogies where the task of analogical persuaders is to convince the audience leap between prior situations and the current one or telling stories.

The researcher resorts to specific models of Persuasive Process. He focuses on the way by which the influence of communication content reflects in individual performance, such conceptualization which was manipulated to show how communicated messages can deliberately affect human behavior. He clarifies two strategies used to explain that. The first conceptualization is called the "psychodynamic model of persuasion process". This model focuses on an effective 
persuasive message saying that it must have properties or the force that changes the psychological functioning of the individual in a way that his answer would be overt with the recommended behavior of the communicator. Thus, the individual's internal psychological structure which affects the psychodynamic relationship between the internal processes that reveals overt behaviors and eventually leads to intentional acts made by the communicators is changed by the effective persuasion. The second concept is the "social and cultural variables" which determine and specify the way people embrace new ideas and things. It can be said that both the psychodynamic and the sociocultural strategies seem to be more linked or attached to the attitudes and their formation. The main goal of the message sender is he focus on the communication process, creating, modifying or reinforcing attitudes and behaviors, and in this respect, the audience are the only ones who decide to evaluate, to reject or accept that message.

Hovland and his colleagues study what influences the success or failure of persuasion via asking 'Who says what to whom and with what effect' and studied three variables realized in persuasion: (a) the communicator, (b) the communication, and (c) the audience. Four steps are added by them in the persuasion process which are namely: attention, comprehension, acceptance and retention. Thus, on these bases and on the three factors mentioned above, Carrel Hovland and his colleagues made the persuasive communication model. It is called K.A.P scale where "K" means knowledge, i.e., the aim is to know to what extent the audience were affected and how much the receiver's knowledge is affected by the information given to him which would affect his opinion on a specific issue. "A" refers to the forming or changing attitudes whereas "P" refers to practice, i.e., achieving change in the receiver's behavior and adopting the desired behavior.

The study concludes that Political and Presidential language has an important role in enhancing the power of persuasion. The research has concluded that Obama has directly and indirectly influenced the audience via using various speech acts where in some cases more than one illocutionary act is found in one utterance. In addition, the study aimed at showing that the use of persuasive speech acts is not used in an arbitrary way but as an effective way to achieve a special political purpose.

\section{The Present Study}

This qualitative study investigates the second inaugural speech of George .W. Bush. Rhetoric and linguistic approach is adopted to reveal the persuasive strategies employed in the speech. Another objective of the study is to shed light on the use of linguistic strategies in Bush's speech.

\subsection{The data}

The data is Bush's second inaugural speech which is openly found in internet. I select this speech for many reasons which are:

1-According to Brooks (2003:1), G.W. Bush is considered as a mangler of English Language and he is known for his overuse of emotional language. He focuses on the use of negatively charged emotional language.

2-Dependency -creating language and the language of contempt and intimidation are employed by Bush to shame others into submission and desperate administration.

3-The main characteristic attributed to Bush is talismanic or symbolic war man. He usually delivers his speech with a voice which is a high-pitched petulant whine.

4-He has the ability to project himself in many cases as a stereotypical male, in another sense as a trustworthy leader.

5- Bush usually mispronounces words and in many cases he uses wrong words.

6-Bush usually uses the syntax that degenerates into anacoluthon with a tone often off in an ambiguous way.

7-Bush always resorts to use empty language technique in which broad statements are used. These statements are abstract and mean so little that are impossible to oppose.

8-He also uses personalization technique in which the speaker tends to draw the focus or the attention of the addressee to the speaker personality.

9-Helplessness technique (the language of pessimism) is also used by Bush to generate fear and increase people's sense of vulnerability. This technique motivates people to feel that they are disable to solve their problems.

\subsection{Framework of Analysis}

An eclectic model is adopted based on two models. The former is that of Aristotle's three- stages and the latter is that of Atkinson's linguistic strategies. These two models are not selected randomly but for many reasons which are: (a) they concern with analyzing this kind of speech, (b) they view political speech as a "coherent stream of spoken language that is suitable to be delivered by a speaker to audience to achieve specific purposes on a political occasion" and focus on explaining persuasive strategies. This section provides or reflects the framework of the study. The first model is Aristotle's three- stages model. Three artistic proofs are comprised by Aristotle's model for the analysis of persuasion which are Ethos, Logos and Pathos. These proofs can be reflected by the character, reason and emotion where the first is used to strengthen the relationship between the speaker and the audience. The speaker's character manifests the first proof through his/ her goodwill, virtue and credibility or trust. The speaker resorts to display modesty and present a set of shared values to achieve this proof.

The second proof is an obligatory one because it presents a set of ideas based on arguments which can be of two types: syllogism and enthymeme. The first type is most persuasive. It consists of a major premise; a minor premise and a 
conclusion. The major and minor premise should be right to make the conclusion accepted by the audience whose task is to infer the missing premise which is left unstated to form enthymeme.

The third proof is that aiming to manifest pathos or emotions which are reflected by pleasure or pain. These proofs should suit the different parts of speech which are prologue, the narrative, the proof, the refutation and the epilogue. For example in the prologue, the speaker tries to show ethos and maintain the relationship between him the audience.

The second model is that of Atkinson's linguistic strategies who proposes a set of techniques to describe the persuasive discourse. These techniques affect the audience and can elicit positive audiences' responses expressed by the audience. These techniques are three-element listing, repetition, contrastive pairs, religious citation and the use of first plural pronoun " we".

\subsection{The Analysis of Speech}

The data show that the speech deals with variant topics all of them focus on America and its interests. It discusses issues related to current situations in America with reference to the problems that face the country. In this speech, the president tries to draw the audiences' attention towards his plans for developing different sectors in the society. He talks about two sectors which are the one of health and education. The most common tenses in Bush's speech is the present simple tense and future. The first tense is used to express general events and recite facts while the second is used to show what Bush intends to do in the future. Bush repeats three words many times which are freedom, liberty and democracy. The speech can be divided into four parts which are respectively the prologue, the narrative, the proof and the epilogue. In the first part, Bush seeks to attract or draw the attention of the audience by appealing pathos and ethos. Pathos is reflected when he says, "We have seen our vulnerability - and we have seen its deepest source". Ethos is manifested through directing and repeating his gratitude to the preceded presidents. It is also reflected when Bush depicted himself as that he is the only person who can save the world when he says," We are led, by events and common sense, to one conclusion: The survival of liberty in our land increasingly depends on the success of liberty in other lands. The best hope for peace in our world is the expansion of freedom in all the world". He also says," Our goal instead is to help others find their own voice, attain their own freedom, and make their own way."

The second part of the speech is the narrative one in which Bush justifies or limits the frame for his argument and justifications for what he will say are presented. This part is directed to recite the events that happened in the past. This part is clearly manifested in Bush's words when he says," After the shipwreck of communism came years of relative quiet, years of repose, years of sabbatical — and then there came a day of fire. We have seen our vulnerability — and we have seen its deepest source".

After the narrative part, Bush moves carefully to draw or design the following part which is the proof in which he presents the ideas logically. In this part, Bush seeks to prepare the audience to accept the coming suggestions or arguments. He does his best to make the people ready to share responsibility in solving the problems and difficulties that face the country. Nearly, $60 \%$ of Bush's speech reflects this part but the following paragraph manifests that clearly:

Now it is the urgent requirement of our nation's security, and the call-

ing of our time. So it is the policy of the United States to seek and sup-

port the growth of democratic movements and institutions in every nat-

ion and culture, with the ultimate goal of ending tyranny in our world.

The main appeal that can be found in this proof is that of reason which comes in the form of syllogism when Bush asks American people to share him responsibility as a major premise while shared efforts and hard work reflect the minor one. The major premise is reflected by Bush's words saying:

So it is the policy of the United States to seek and support the growth of democratic movements and institutions in every nation and culture, with the ultimate goal of ending tyranny in our world. This is not primarily the task of arms, though we will defend ourselves and our friends by force of arms when necessary. Freedom, by its nature, must be chosen, and defended by citizens, and sustained by the rule of law and the protection of minorities. And when the soul of a nation finally speaks, the institutions that arise may reflect customs and traditions very different from our own. America will not impose our own style of government on the unwilling. Our goal instead is to help others find their own voice, attain their own freedom, and make their own way.

The following sentences said by Bush reflect the minor premise:

Americans, of all people, should never be surprised by the power of our ideals. Eventually, the call of freedom comes to every mind and every soul. We do not accept the existence of permanent tyranny because we do not accept the possibility of permanent slavery. Liberty will come to those who love it. Today, America speaks anew to the peoples of the world: All who live in tyranny and hopelessness can know: the United States will not ignore your oppression, or excuse your oppressors. When you stand for your liberty, we will stand with you. Democratic reformers facing repression, prison, or exile can know: America sees you for who you are: the future leaders of your free country. 
Bush presents the conclusion to these two sides when he concludes saying:

Our country has accepted obligations that are difficult to fulfill, and would be dishonorable to abandon. Yet because we have acted in the great liberating tradition of this nation, tens of millions have achieved their freedom. And as hope kindles hope, millions more will find it. By our efforts, we have lit a fire as well —a fire in the minds of men. It warms those who feel its power, it burns those who fight its progress, and one day this untamed fire of freedom will reach the darkest corners of our world.

Ethos also penetrates the proof many times when Bush presents himself as the only person who can solve all the difficulties and obstacles that face the world as in," My most solemn duty is to protect this nation and its people from further attacks and emerging threats".

The last part of speech is epilogue in which Bush summarizes key points of his argument and refers back to the previous section showing the need for being unified and hard workers as in:

We go forward with complete confidence in the eventual triumph of freedom. Not because history runs on the wheels of inevitability; it is human choices that move events. Not because we consider ourselves a chosen nation; God moves and chooses as He wills. We have confidence because freedom is the permanent hope of mankind, the hunger in dark places, the longing of the soul.

All of what has been said above deals with the Aristotle's model; therefore a next step to clarify or explain linguistic strategies is required. These strategies contribute to the success of Bush's speech. The use if three-element listing is one them. This strategy strengthens the discussion and argument. The most important word in Bush's speech is freedom which is replaced by many synonyms such as,

There is only one force of history that can break the reign of hatred and resentment, and expose the pretensions of tyrants, and reward the hopes of the decent and tolerant, the best hope for peace; and America's vital interests and our deepest beliefs.

The second linguistic strategy is that of the repetition of the form and the content. The first one is exemplified in the multiple uses of the same vocabularies and parallel structures. The word ' freedom' for example is repeated more than forty times. Bush resorts to the parallel structure such as' after the shipwreck of communism came years of relative quiet, years of repose, years of sabbatical — and then there came a day of fire'. 'We have seen our vulnerability — and we have seen its deepest source' and' across the generations we have proclaimed the imperative of self-government, because no one is fit to be a master, and no one deserves to be a slave'.

Contrastive devices form another technique in which on argument is contrasted with another in a way that the speaker's preferred position is seen superior such as, 'America's influence is not unlimited, but fortunately for the oppressed, America's influence is considerable, and we will use it confidently in freedom's cause; and 'America will not impose our own style of government on the unwilling. Our goal instead is to help others find their own voice, attain their own freedom, and make their own way'.

Religious citation technique as well as the overuse of first personal plural pronoun belongs to linguistic strategies followed in this genre but they will not be discussed in this study because they are employed clearly and overly by Bush and all the preceded presidents.

\section{Conclusion}

The research investigates the second inaugural speech delivered by Bush on Thursday, January 20, 2005. A rhetorical analysis based on Aristotle's three-stage model and linguistic strategies of Atkinson are adopted to achieve this purpose. The results show that this speech is a successful one because it satisfies the conditions and maxims of these two models. The appearance of three tenses is obligatory one due to the fact that present tense is used to reflect the current situation while future simple tense denotes Bush's view of the future. Past tense is used to clarify Aristotle's narrative part. Bush exploits Aristotle's artistic proofs carefully to convince the audience accepts his point of views. Linguistic strategies are also exploited by him specially that of repetition of the word 'freedom'. He forgets that the choice of the government system of each nation depends on or is the result of its particular culture and its specific level of development; therefore, the word 'freedom' brings catastrophes to my country (Iraq).

\section{References}

Burke, K. (1969). A Rhetoric of Motives, Berkley, CA: University of California Press.

Chouliaraki L., and Fairclough, N.1999.Discourse in Late Modernity: Rethinking Critical Discourse Analysis. Edinburgh: Edinburgh University Press.

Cyphert, D. (2010). The rhetorical analysis of business speech: Unresolved questions. Journal of Business Communication, 47,346-368.

Fotheringham, (1966). Perspective on Persuasion. Allyn and Bacon. 
Hague, R., M. Harrop, and S. Breslin (1998). Comparative Government and Politics: An Introduction, Basingstoke, Macmillan, $4^{\text {th }}$ edn

Holt, R., \& MacPherson ,A. (2010). Sensemaking, rhetoric and the socially competent entrepreneur. International Small Business Journal, 28,20-42.

Jones, B.(ed.) (1994). Politics UK, $2^{\text {nd }}$ edn, New York, Harvester Wheatsheaf.

Meyer,T. (2000). Was ist politik? Opladen.

Perelman, L.,\&L. Olbrechts. Tyteca (1969). The New Rhetoric: A Treatise on Argumentation . Notre Dame: Notre Dame Press, Print.

Plett, H. (2001). Einfuhrung in die rhetorische Textanalys, Hamburg: Buske.

Sillince, J., \& Suddaby, R. (2008). Organizational rhetoric: Bridging management and communication scholarship. Management Communication Quarterly, 22, 5-12

Wodak, R. (1997). Critical Discourse Analysis and the Study of Doctor- Patient Interaction In Gunnarsson, B.- L., Linell, P., and Nordberg, B.(eds), The Construction of Professional Discourse. London: Longman.

(2004)." Critical Discourse Analysis." In C.Seale, G-Gobo,J.F. Gubrium ,\& D. Silverman , Qualitative ResearchPractice ( pp.197-213). London: Sage. 